Maê Nascimento

The Space of Silence

International Institute for

Bioenergetic

Analysis

2005 (15)
Bioenergetic Analysis

15. Volume, No. 1, 2005, Page 89-100

Psychosozial-Verlag

DOI: 10.30820/0743-4804-2005-15-89

\title{
蓲 Psychosozial-Verlag
}


Bibliographic information of Die Deutsche Nationalbibliothek (The German Library) The Deutsche Nationalbibliothek lists this publication in the Deutsche Nationalbibliografie; detailed bibliographic data are available at http://dnb.d-nb.de.

2005 Psychosozial-Verlag GmbH \& Co. KG, Gießen, Germany

info@psychosozial-verlag.de

www.psychosozial-verlag.de

\section{(C) $(1) \Theta \Theta$}

This work is licensed under the Creative Commons Attribution-NonCommercialNoDerivatives 4.0 International License (CC BY-NC-ND 4.0). This license allows private use and unmodified distribution, but prohibits editing and commercial use (further information can be found at: https://creativecommons.org/licenses/by-nc-nd/4.0/). The terms of the Creative Commons licence only apply to the original material. The reuse of material from other sources (marked with a reference) such as charts, illustrations, photos and text extracts may require further permission for use from the respective copyrights holder.

Cover layout: Christof Röhl

Editorial staff: Kristine Klein

Layout: Katharina Appel

https://doi.org/10.30820/0743-4804-2005-15

ISBN (PDF-E-Book) 9978-3-8379-6805-7

ISBN (Print) 978-3-89806-395-1

ISSN (Online) 2747-8882 · ISSN (Print) 0743-4804 


\title{
The Space of Silence
}

\author{
Maê Nascimento
}

\section{Introduction}

Today Bioenergetic Analysis, and psychotherapy in general, must be evaluated within a larger context of our professional history, new findings, and our understanding of knowledge itself. In this short paper, I want to introduce what I consider to be an essential ingredient to such evaluation and to therapy itself - the space of silence. This is an inner place which the therapist consciously accesses, in order to reduce the continuous interference from the Ego and to become available to issues and information coming up in the therapist-client relationship.

To get there, I paint a very large canvas about knowledge and psychotherapy. I ask what we can learn from new concepts of the Self, from developments in neurobiological research and Physics. I ask what these insights portend for our perspective on health, disease and cure. This then leads to a consideration of new roles for the therapist. For simplicity's sake, I use the feminine pronoun in referring to the person.

\section{The human being in modern psychology}

Psychoanalysis was the first scientific theory to describe psychic functioning, how disturbances in this functioning contributed to disease and to provide a method for achieving psychological health. Sigmund Freud's insight into the intrinsic connection between Biology and Psychology was revolutionary. For this, he has been considered as the father of psychosomatic medicine. According to Freud's perspective, sexuality is the central focus in the human psyche and his views about pathology include a somatic basis for symptoms.

He created his theory in morally restrictive times, and his concepts and methods were cloaked in an atmosphere of secrecy. I have always pictured in my mind that when Freud's clients spoke up their associations, they 
might sound like whispering secrets, so 'prohibited ‘ were Freud's discoveries regarding sexuality.

Repressed material (which Freud always interpreted as sexual) had to do with a natural vitality that could not be experienced and expressed let alone valued. Freud's boldness in bringing sexuality to light was only partially successful. The sexual (thus biological) nature of psychic functioning/mal-functioning was described and analyzed only from a mental perspective.

It was Wilhelm Reich who formed the vanguard of a new position, proposing that pleasure and vitality could free human beings, allowing them to have a wider range of expression. With his Functional identity concept ${ }^{1}$ he joined the biological (the body) and the psyche into a totality through which the individual can be seen and through which the individual expresses herself in life. He also created the concept of the orgone, the universal vital energy in human beings and the cosmos.

Nevertheless, repressive forces of Fascism and Nazism rose to a peak at that time, which produced a disconnected mind of submission. This repressive process eventually produced many revolutionary movements, claiming new values and ways of being. These movements appeared everywhere, perhaps with an apogee in the sixties with the multitude of movements around expression, of recovering senses and sensuality, giving room for the body as a focus. Those movements also emphasized love and peace, sexual freedom, community, gender equality and the like. New values were expressed by the Hippies, the Women's Liberation Movement, ecological awareness, anti-war sentiment, etc. They spoke of a new human being, more integrated and loving, throwing off the shibboleths of the past.

Psychology also reflected these times with new approaches to old problems - Psychodrama, Gestalt, Client Centered Therapy, Transactional Analysis and Bioenergetic Analysis. These psychotherapies brought in the scope of their theories an integration of sensation, feeling and thinking, and were humanistic in orientation. Everything seemed new and people

1 »The concept of Functional Identity ... only means that muscular attitudes and character attitudes have the same function in the psychic mechanism: they can replace each other and influence one another. They, basically, can not be apart. They are equivalent in their roles « (Reich 1977, p. 230). 
were starting a wider and popular learning about themselves in the quest for >authenticity< in living.

\section{The context of psychotherapy}

Daniel Goleman writes: »Psychology theories are shaped by self-biography: The author's personal history has direct influence over their theoretical constructions " (Goleman 1980, p. 33). Perhaps this helps to explain the reason why certain personal characteristics are learned as required attributes to the role of therapists or in their methods. Take Freud and Reich, for example: These new psychotherapeutic theoreticians were strong, determined and assertive men who totally believed in their ideas and concepts. Because they were bringing very new insights about the person, they faced opponents and resistance, but fought fiercely to have their approach and methods understood and they did so in a consistent and vigorous way. I think we can ssee this vigor and firmness in their descriptions of therapeutic techniques, leading to the impression that those traits should be part of >being a therapist $<$.

Bioenergetics was also innovative in its time, with its conceptualization about energy and its view of the body. Such innovation might have motivated close surveillance as part of its teaching. This could be one reason for Alexander Lowen's and John Pierrakos' firm and personal attitudes being taken as part of the required attitude developed by many Bioenergetic therapists. At some point, it has been yet considered as a directive psychotherapy approach, with the therapist looking at the client's body, making a diagnosis assessing the issue and suggesting rexercises to the client. The client is supposed to trust the therapist and follow his instructions. Perhaps also in those opening and changing times people needed parameters for the new ways of thinking and behaving. Thus strong and authoritarian leaders who model rassertiver techniques would provide their clients and students with a feeling of being safe and protected in tracing a new path.

Some decades later, however, the scenery has changed - and perhaps therapeutic needs as well. The present time demands decreasing interference coming from the world over the person, a ceasing of the excessive demands of the past. 
People, now, would rather seek inside themselves for dealing with issues which, in the past, were posed to parental figures from outside such as the therapist.

\section{A perspective based on today's knowledge}

At this moment in time we are in transition to a new paradigm. Before introducing it, though, we should look at the process of knowledge itself. Throughout history, mankind has been going through an evolutionary path which is continuously changing.

»Development trajectories unfold in a spiral movement in both, individual and collective instances. Our existence follows an evolutionary pattern, going from simpler to more complex levels « (Basso \& Pustilnik 2000, p. 18). This statement is yet supported by Psychology researchers in the field of child development.

Paradigms are organizing structures to aid us in our process of learning about the Universe. When formed, they give a new way of seeing the world and at a certain point they are discarded when new ones are formed. But when a paradigm is discarded, the knowledge it provided does not >die< - it is transformed and incorporated into a new one.

Physics exemplifies this perhaps better than any other discipline. Until the middle of the $20^{\text {th }}$ Century we lived in a Newtonian/Cartesian world, a world which was described as being solid, predictable and governed by defined rules. The mode of thinking and understanding was largely deductive and linear. Reality concepts were demonstrated by mathematical equations.

With the advent of Quantum and Chaos theories this world was turned upside down and the deterministic views of the past were questioned. From Physics we learn that atomic particles are neither solid nor predictable. They just Potentially exist (existing within certain probabilities). »Quantum Physics provides us with supportive data for intuitive phenomena which were implicit in all fields (mainly in Human Sciences) but could not be given a scientific status, since . . . they do not produce absolute mathematical equations «(Basso \& Pustilnik 2000, p. 58). From these points of view, two inferences arise, both crucially important to the approach of the knowledge process: 
Today's concepts of the Universe suggest mutant and unpredictable matter, which does not necessarily exist at defined places, but has a probability, a tendency of occurring.

A phenomenon can not be separated from its observer, the one who shapes it in a certain time and place.

Those new concepts may suggest to us the idea of reality as being conscience which is expressed in the individualized (each one of us) consciousness and in mankind's collective consciousness.

This new perspective widens Psychology's scope and many of its key concepts, like health, disease and cure, may need to be reformulated or changed.

In Freud's theory, the concept of health is associated to the degree of Ego's development along the infantile period. There are many complex variables in this process: But to put it in a simple way, the Ego is the mediator between the person and the environment. It is the Ego then which sets the degree of adjustment or deviation from moral/ ethical/ behavioral codes. Reich's theory as well as Bioenergetics, have demonstrated the functional role of the Ego in the concept of character: Ego builds up a personality based on defensive mechanisms enhancing the person's being in the world in a more or less acceptable and 'painless c condition.

Ego, thus, has to do with social image, with what is expected from each person considering environmental conditions. Ego results from conditioning processes.

But we shall claim that the person is much more than her slearned reactions and probably for this reason, the concept of self has been receiving more and more focus.

\section{Supportive concepts from the neurosciences}

»The self can be seen as an integrative principle, operating at each and every level of development ... As an organizing entity, it guides evolution through wholeness, and its perception can be a source of inspiration and healing " (Basso \& Pustilnik 2000, p. 60). The issue of the Self being an individualized particle coming from the Universe totality cannot be seen as matters exclusive to Philosophy or Religion like they were in the past. 
As I said, the new metaphor refers to a concept of reality which does not exist as fixed and settled independently of our attention. Instead, we deal with a potential reality being shaped according to our attention and perception of it. This perspective is supported by research in the neurosciences. I will report on these findings, in order to aid us in our comprehension of it.

Prior to the sixties/seventies, knowledge of the critical importance of the Central Nervous System was limited. It was seen as an electrical communication system where nervous transmissions occurred exclusively through synapses - electrical impulses going from one neuron to another, like walking sstep by step $<$. The electrical brain was considered as the only one in charge of intellect and consciousness. If this was the correct description of its real nature, we would have pre-determined restrictions on our capacity to learn, according to the number of nervous terminations existing in our brain. In the late seventies, though, there was a radical change and new findings pointed to the existence of chemical substances and processes in the brain. These were referred to as transmitters and receptors and comprised the real information network.

According to Candace Pert (1999, p. 66), »We call transmitters any component, either natural or synthetic, which makes a connection to its specific receptor molecule in the cell's surface ... This transmitter, colliding and entwining [to the receptor] is what we call liaison (to connect) and in this process, it carries on the message - through molecular qualities, into the receptor (...) Receptors are molecules composed by proteins and they gather in a bunch in the cellular membrane, waiting for the right chemical >keys ' which will come >swimming ‘ through the extra-cellular fluids to meet them and to connect to them. These are the transmitters moving throughout the body, and when meeting their receptors, they connect and disconnect as in a network, in a simultaneous way, carrying information. The receptors work, basically, as sensing and sensorial molecules ... they work as sensorial organs, just at the cellular level. They flow over the membrane of cells ... dancing and vibrating, waiting to get the messages from other vibrating particles [the transmitters] which come across the cells. They are in continuous movement, in a rythmic and vibratory way... The connecting process is very selective, since receptors simply ignore all transmitters that are not meant to match or entwine with them «. This is 
The Space of Silence

a fascinating description of the information network, which works all through the body, providing a biochemical foundation for emotions.

In the Eighties transmitters and receptors have come to be known as information molecules, producing a cell's language system for communication among endocrine, gastric, neurological and immunological systems. We see, then, that the information system of the >biochemical brain ‘ works in accordance with the notion of totality and integration. Moreover, with information being an essential part of the process, we might assume that there is intelligence shaping systems and creating behaviors - not casual, random or intellectual, but an intelligence which is organizing, harmonizing and provides meaning. This intelligence is not an exclusive human quality, it comes from the Universe. As I see it, it does not work in deterministic ways, but as a tendency to integration and harmony.

\section{New frame - new human being}

Many authors have been referring to the concept of self, but with many different meanings. The self referred to in this paper is the same as used in Analytical Psychology and in Transpersonal Psychology: Its main idea has to do with the idea of totality.

"A human being is one part in a whole which we call >Universe $<-$ a part which is restricted to a certain time and space. She experiences herself, her thoughts and emotions as being separated from the whole - as in an optical illusion of the consciousness " (Einstein 1985, p. 13)

We are, then, a part within the wholeness of the $>$ Universe $<$. From this perspective, each human being can experience herself as an Independent Self in her searching for wholeness. The Self encompasses everything a person is, even potentially and is far beyond what she learns throughout her life-span. The Self can be seen as possessing an endless source of qualities which, under appropriate conditions, can be revealed. Carl G. Jung wrote that "nobody understands what the Self is, because the Self is everything you are not - it is not the ego. The ego finds itself as an appendix of the Self « (Jung 1971, p. 31). In a similar statement, John Pierrakos describes the CORE as "... the centre of the individualized life ... it is the whole human capacity, a vital and luminous mass, the source and the 
conscience of the Vital Force "(Pierrakos 1990, p. 27). Considering that these concepts convey the qualities of wholeness and the possibility of human potential to be developed by each living person, we are reasoning here in accordance with the new paradigms.

\section{New parameters for health, disease and cure}

Health denotes integration. »Perfect mental health is fully connected to all other components of well-being. Wholeness, thus, depends on a balanced integration among the physical, mental, emotional, existential and spiritual levels of consciousness « (Vaughn 1980, p. 20). We live in a world with increasing levels of agitation and noise, and people, at least in Western cultures, try to adjust to this condition. As a consequence, the focus is kept outside the Self often with a frantic search for status and power, >success $>$ and wealth. This condition leads to psychic numbing, fragmentation, and to a progressive loss of connection to the Self, to the truest and deepest being inside us. It also means identification with the Ego as Self. This can be considered as a new framing of disease or dysfunction.

The person who has the Ego as a guide for her thoughts and behaviors restrains her potentiality to be in accordance with sapproved emotions, feelings and thoughts. She also represses or denies healthy qualities resulting in conflicts and suffering. This process works on the vital energy flow by blocking and freezing and denying authenticity. As posed by Reich and Bioenergetics, the energy flow becomes fragmented, bringing distortions to the whole natural balance of the organism. Blocked energy reduces selfawareness and prevents consciousness from expanding through experience. The person stands stuck, devitalized and unable to feel herself into the experience of growing. As John Pierrokos points out:

"From the perspective of our essential being, dysfunction comes about from unnatural flow of energy inside the organism . Dysfunctions are, then, expressed through denial patterns, which have common characteristics, but show unique combination in each individual« (Pierrakos 1990, p. 84).

Healing, then, has to do with dis-identifying Self from Ego and restoring connection to the vital energy flow which forms the Self. Free energy flowing 
The Space of Silence

represents the possibility, for all of us, of full realization of who we truly are, and this is provided by Self connection through consciousness. This quality restores to the person the condition of Wholeness - within herself and with the Universe.

\section{A new therapeutic process}

The process of dis-identification from the Ego and re-connection to the Self is very complex and not in the scope of this paper. However, I want to point out that this transformation requires the therapist to change his internal attitude. This change will reflect on his way of relating to the client. As I mentioned before, the healing process refers to mobilizing blocked energy altogether with its respective psychic contents. I refer here to what we know as character issues, which need to be worked through to allow awareness and integration. This condition gives Bioenergetics a privileged position as its main focus tends to be the energy in the body and its correspondent personal expressions. Yet, the Bioenergetic therapist must also be acutely aware of certain conditions in the therapeutic relationship which are related to her new internal attitude.

First of all - and this turns out to be a major transformation for those therapists who see their role as directive - directions do not come from a mental / Ego place. They come through the energy flow in the body, which, when it is allowed, will find its proper way. In order to apprehend those directions, the therapist must be in a listening / observing, rather than sprocessing $<$, mode. To be truly in that place, the therapist must shut up his own Ego chitchat, stopping its continuous judgmental interference. She needs to be in contact with her own Self so that she makes room for an open and exempt perception of her own and the client's expressions. In this place pre-judgements and programs are suspended. This is the space of silence. From this place she will be able to identify which kind of help the client may need and to be available to provide this help. 


\section{The space of silence}

When the therapist goes to the space of silence two important consequences occur.

By staying connected with her Self, without splitting or conflicts, the therapist will stimulate a similar condition in the client. There is therefore resonance between them. It allows the therapist to find a truly receptive, compassionate, empathetic, and respectful attitude toward the client. The client, then, will hopefully be more able to express conflicts and contradictions, trusting that the therapist is there for her. In fact, this is the primary need of the client, as there is no right or wrong, good or bad in this place. Instead there is full acceptance of whatever the Self expressions are, allowing a space to their experience and integration.

The space of silence is crucial for allowing self-awareness and for enhancing the growth and maturation process, of both the client and the therapist.

The space of silence must be activated in a conscious way by the therapist.

In order to arrive there, the therapist must focus her attention on her breathing and its route through the back along the spinal medulla. Emphasis is placed on exhalation rather than inhalation (remember, you want to clear this space). After a few minutes of this procedure, silence and calm gradually replace the noise caused by the usual flow of thoughts from the Ego. There is where the therapist will find an empty space, cleared from all inconvenient interference, allowing her to receive information coming from the therapeutic relationship. As this flow of information is not under Ego control, you get a wide range and exempt quality of perception. Since this is a non-conventional type of breathing, it requires attention to keep it focused. This enhances intention and guarantees the therapist's full presence. At some point, the therapist will face, of course, resistance coming from the client, as defense mechanisms are activated by the Ego. Once this process is identified, the therapist will assist the client to comprehend as well as to overcome these forces, thus allowing freedom to expand and self-knowledge to grow. Distinguishing defensive behavior from the Self's true expression is part of the therapist's responsibility. To be able to accomplish this task, the therapist must be receptive to the flow of information within an egoless perception. This condition provides 
essential wisdom to come out for both client and therapist. From this perspective, the therapist is a partner who supports and accepts the truth of the client's self-expression in a journey of mutual expansion.

\section{Conclusion}

To be in the Space of Silence approximates a meditative condition and therefore, it requires a continuous practicing of one specific mode of breathing.

If this condition is often activated, the access to the Space of Silence will be progressively faster and natural.

For the therapist, the Space of Silence represents a condition of peace, where there is no room for expectations or directiveness of any kind. In fact, it can be felt as a blessing, as continuous ego pressure about >doing the right thing s tends to cease.

Besides being an essential tool to be used in the therapy situation, the Space of Silence goes far beyond. Being there in the context of daily life can keep us safe from the intensive pressures we suffer from the world, which are the main reason for stressful and conflictual situations. Moreover, the Space of Silence creates for the person an introspective capacity, as well as more peaceful connections among people. This might help to clean the atmosphere for the planet too.

The Space of Silence is a space of discovery and health, wherein integration shapes connection between human beings and the Universe, creating a path of loving and harmonic energy.

\section{References}

Basso, T \& Pustilnik, A. (2000): O Inconsciente emergente. Sao Paolo (Inst. Dinâmica Energética do Psiquismo).

Einstein, A. In: Vaughn F. (1985) (Ed.) Novas dimensões da cura espiritual. Sao Paolo (Ed.Cultrix / Pensamento).

Goleman, D. (1980): Perspectivas em Psicologia, realidade e o estudo da consciência. In: Walsh R. \& Vaughn F. (1980) (Eds.): Além do Ego. Sao Paolo (Ed.Cultrix / Pensamento), pp. 32-39. 
Jung, C.G. (1971): Psychological Commentary on Kundalini Yoga , Zürich (Spring Publications).

Pert, C. (1999): Molecules of emotion - Touchstone. In: Basso, T. \& Amaral, M. (2000) (Eds.): Dermatomos. Sao Paolo (Inst.Cult. Dinâmica Energética do Psiquismo). Pp. 66-84.

Pierrakos, J. C. (1990): Energética da Essência. Sao Paolo (Ed Pensamento). Reich, W. (1977): A função do orgasmo. Sao Paolo (Ed. Brasiliense).

Vaughn, F. (1985) (Ed.): Novas dimensões da cura espiritual. Sao Paolo (Ed.Cultrix / Pensamento). Pp. 19-36.

\author{
Maê Nascimento, lic.psychol., \\ Rua Zaira, 245 - Pinheiros, \\ 01252-060 São Paolo SP, Brazil, \\ E-mail: maenascimento@terra.com.br
}

